TRABAJOS DE PREHISTORIA

68, N. ${ }^{\circ}$ 1, enero-junio 2011, pp. 187-198, ISSN: 0082-5638

doi: $10.3989 /$ tp.2011.11066

\title{
Orígenes del dorado por amalgama: aportaciones desde la orfebrería protohistórica del noroeste de la Península Ibérica
}

\author{
On the origins of mercury gilding: contributions from the Protohistoric goldwork \\ of Northwest Iberia
}

Marcos Martinón-Torres (*)

Lois Ladra (**)

\section{RESUMEN}

Los orígenes y difusión de la técnica del dorado por amalgama de mercurio siguen planteando numerosos interrogantes. Recientemente se ha sugerido la posible existencia de un foco independiente para la invención de esta técnica en el sur de la Península Ibérica (Perea et al. 2008). En este artículo se presentan los análisis por fluorescencia de rayos $\mathrm{X}$ (FRX) de dos fragmentos de torques protohistóricos del noroeste de la Península Ibérica dorados por amalgama, que constituyen la evidencia más temprana de dicha técnica en esta región. La tecnología y el estilo de estos objetos plantean la posibilidad de contactos y transmisión tecnológica a lo largo de la fachada atlántica europea. En consecuencia, estos hallazgos nos obligan a diversificar los modelos explicativos para la difusión de esta técnica.

\begin{abstract}
The origins and transmission of mercury gilding remain unclear. Recently, the possibility of an independent focus of invention in the South of the Iberian Peninsula has been proposed (Perea et al. 2008). Here we present analyses by portable X-ray fluorescence (XRF) of two torcs from the Northwest of the Iberian Peninsula that reveal the earliest evidence for this technique in the region. The technology and style of these artefacts raise the possibility of contacts and technological transmission on the Atlantic coast of Europe. Thus, these finds call for a di-
\end{abstract}

(*) Institute of Archaeology, University College London. 31-34 Gordon Square, London WC1H OPY, Reino Unido. Correo e.: m.martinon-torres@ucl.ac.uk

(**) Lúnula - Servizos Profisionais de Patrimonio Cultural e Arqueoloxía. Correo e.: lunulapatrimonio@gmail.com

Recibido: 9-VI-2010; aceptado: 15-XI-2010. versification of the explanatory models for the difussion of this technique.

Palabras clave: Oro; Torques; Arqueometría; Arqueometalurgia; FRX portátil; II Edad del Hierro; Europa Atlántica.

Key words: Gold; Torcs; Archaeometry; Archaeometallurgy; portable XRF; Late Iron Age; Atlantic Europe.

\section{INTRODUCCIÓN}

Hace más de treinta años, Linns y Oddy (1975) lamentaban la falta de investigación sistemática sobre los orígenes de la técnica del dorado por amalgama de mercurio, una pobreza que contrastaba con la abundancia de conjeturas carentes de fundamento científico. En los años transcurridos desde entonces, se ha incrementado el número de trabajos que identifican convincentemente el uso de esta técnica en diversos contextos (véase, en especial, La Niece y Craddock 1993; DraymanWeisser 2000), pero el asunto de la cronología temprana y difusión del dorado por amalgama sigue conteniendo muchas incógnitas. Si bien está claro que esta técnica es la preferida en toda Europa desde la época romana tardía, su incidencia en épocas anteriores parece más difusa y confusa.

En un trabajo de revisión reciente, Perea et al. (2008) han retomado este problema, prestando particular atención al caso de la Península Ibérica, para presentar una interesante sugerencia: la posibilidad de que esta técnica se hubiese inventado en el sur de la península, en algún momento de la segunda mitad del I milenio a.C., con inde- 
pendencia de otras posibles invenciones en el Mediterráneo y en Europa. Aun cuando la propuesta de estos autores es coherente con los datos disponibles, ellos mismos reconocen que siguen faltando análisis que permitan establecer un mapa más claro de los orígenes y difusión de esta técnica (Perea et al. 2008: 117).

En este artículo se presentan nuevos análisis de dos objetos dorados por amalgama recuperados en el noroeste peninsular y que, hasta donde podemos saber, constituyen la evidencia más temprana del empleo de dicha técnica en esta zona de la península. El estudio no resolverá nuestro problema fundamental, pero sí se espera que añada diversidad a la cuestión, ya que plantea la posibilidad de influencias atlánticas, y no necesariamente mediterráneas, en la difusión de la técnica.

\section{EL DORADO POR AMALGAMA DE MERCURIO: FUNDAMENTOS TÉCNICOS Y EVIDENCIAS TEMPRANAS}

El dorado por amalgama de mercurio es una de las varias técnicas empleadas a lo largo de la Historia para el dorado metalúrgico, es decir, aquél que busca modificar la apariencia superficial de metales menos nobles que el oro. Sin embargo, constituye la técnica más popular en el Viejo Mundo durante un largo período que discurre desde la época romana tardía hasta el descubrimiento del dorado por electrólisis en el siglo XIX d.C., aun cuando coexiste con otras técnicas como el dorado mediante pan de oro, el chapado y el dorado por difusión, entre otras posibilidades (Oddy 1993, 2000).

El éxito de esta técnica se explica por la disponibilidad de mercurio pero también, sin duda, por la relativa facilidad y buenos resultados que ofrecía en comparación con otras. En esencia, el dorado por amalgama de mercurio o dorado al fuego se basa en la propensión que tiene el mercurio a formar aleaciones con metales nobles a temperatura ambiente o calor moderado, así como en la volatilidad de este peculiar metal. La descripción de esta técnica y sus variantes ya se ha descrito sobradamente en otras publicaciones, incluyendo trabajos experimentales de reproducción (Anheuser 1996, 1997; Murakami 2000; Northover y Anheuser 2000; Blet-Lemarquand et al. 2009). Los orfebres comenzarían por producir la amalgama separadamente, quizás sometiendo a un leve calentamiento el mercurio con virutas o limaduras de oro. Pos- teriormente, la pasta obtenida (una mezcla de partículas de oro, mercurio y amalgama) se aplicaría en la superficie del metal a dorar. A continuación, la pieza se sometería a temperaturas inferiores a $500^{\circ} \mathrm{C}$ (idealmente, en torno a $250-350^{\circ} \mathrm{C}$; Anheuser 1997; Northover y Anheuser 2000), lo que provocaría la evaporación de gran parte del mercurio, dejando una capa rica en oro adherida a la superficie del objeto. De juzgarlo necesario, los orfebres podrían repetir esta operación varias veces, hasta obtener un dorado de calidad satisfactoria. Las superficies doradas por amalgama son muy porosas, dado que han perdido gran parte de su masa durante la evaporación del mercurio. Sin embargo, un simple bruñido proporciona una superficie lisa y brillante.

Apoyándose en referencias un tanto confusas de historiadores de la Antigüedad Clásica, autores como Oddy $(1993,2000)$ han sugerido la posibilidad de que, en épocas tempranas, el dorado por amalgama pudiese realizarse en frío. Algunos intentos de reproducir esta técnica han fracasado (Anheuser 1996), aunque el propio Oddy (1993: 178) menciona que la técnica todavía se empleaba en Baviera a finales del siglo XX d.C. También se han considerado variantes como la aplicación de un pan de oro directamente sobre una capa de mercurio en la superficie de la pieza, en lugar de la formación de amalgama como paso previo independiente.

Cualquiera que sea el caso, parece claro que el dorado al fuego conlleva difusión de mercurio al sustrato metálico, de modo que siempre quedan trazas de éste en las superficies doradas mediante esta técnica. Al menos, no conocemos ningún trabajo experimental donde el mercurio se eliminase totalmente durante el calentamiento. Por tanto, parece razonable asumir que, si se emplean técnicas analíticas adecuadas, el mercurio puede identificarse positivamente en las superficies doradas al fuego.

Las evidencias más tempranas y convincentes de dorado por amalgama están en China, en torno al siglo V a.C. (Jett y Chase 2000). En Occidente, objetos con este tipo de dorado aparecen esporádicamente algo más tarde, en torno al siglo IV a.C. De este período datan los anillos griegos de período helenístico estudiados por Craddock (1977), pero también los broches de La Bienvenida-Sisapo en Sierra Morena, que aparecen entre los siglos III y I a.C., pero cuya cronología podría retrotraerse hasta el siglo IV a.C. 
(Perea et al. 2008). También es posible que se emplease esta técnica en un pendiente procedente de l'Illa d'en Reixac (Ullastret, Girona) en el nordeste (Rovira Hortalá 1999: 242), aunque la presencia de mercurio en esta pieza no se ha demostrado analíticamente (C. Rovira Hortalá, com. pers. 2010). No es sorprendente que sea en estas áreas geográficas donde encontramos las primeras evidencias de esta técnica, dada la disponibilidad de mercurio en diversos yacimientos de la zona central y meridional de la península (Domergue 1987; Zarzalejos et al. 1999; Matías et al. 2000-01). Más problemático es el tema de su difusión. Como en tantas innovaciones documentadas arqueológicamente, no es posible determinar con certeza si la técnica se transmitió progresivamente desde China hacia Occidente o si, por el contrario, encontramos varios focos de invención independientes (a favor de la segunda propuesta, Perea et al. 2008). Para el área europea, también es destacable que la técnica tarde tanto en implantarse, ya que transcurren varios siglos desde los primeros ejemplos puntuales hasta que la amalgama se establece como técnica de dorado predominante. Como ya indicó Oddy (1993, 2000), probablemente no sería rentable y eficiente mientras no se desarrollaron métodos efectivos de destilación del mercurio a partir del cinabrio. En la Europa Atlántica, el dorado al fuego parece llegar aún más tarde que en la zona mediterránea: los primeros ejemplos documentados se hallan en algunos de los torques del conjunto de Snettisham (Norfolk, Inglaterra), donde sólo algunas piezas son doradas por amalgama, mientras que otras son doradas por oxidación y otras no presentan tratamiento superficial (D. Hook, com. pers. 2010). No obstante, la técnica no se implanta con solidez hasta la época romana (Northover y Anheuser 2000). Sin embargo, hasta ahora no conocíamos ningún ejemplo del empleo temprano del dorado por amalgama en el área atlántica de la Península Ibérica. Los dos objetos que presentamos en este estudio comienzan a visibilizar esta zona del mapa.

\section{BREVES CONSIDERACIONES SOBRE LA CRONOLOGÍA DE LA ORFEBRERÍA PROTOHISTÓRICA DEL NOROESTE DE LA PENÍNSULA IBÉRICA}

La práctica totalidad de los investigadores ha asumido desde hace casi un siglo unas dataciones claramente prerromanas para la denominada "orfebrería castreña", pero esta eventualidad aún no ha podido ser resuelta de manera concluyente y definitiva. Dos son las principales razones que nos permiten explicar esta situación. Por una parte, no se han identificado necrópolis de la Edad del Hierro con ajuares funerarios que incluyan elementos típicos de la "orfebrería castreña" como torques o arracadas. Por otra, la mayor parte de los descubrimientos son hallazgos casuales y sin excavaciones con dataciones radiométricas asociadas.

La gran mayoría de los torques han sido recuperados en el interior de poblados fortificados con una marcada diacronía en su ocupación, a veces incluso encuadrada entre los finales de la Edad del Bronce, la totalidad de la Edad del Hierro y gran parte de la romanización. Todo ello sin olvidar que el uso de la orfebrería en comunidades premodernas cuenta con numerosos paralelos etnográficos de transmisión intergeneracional como elementos dotados de un elevado contenido simbólico, reforzado por mecanismos hereditarios. Siendo así, incluso el contexto arqueológico en el que este tipo de objetos podría ser recuperado en condiciones controladas, no dejaría de poder ser cronológicamente posterior al de su elaboración original (Ladra 1999).

Las numerosas analogías formales y materiales perfectamente documentadas en la orfebrería de diversas comunidades de la Edad del Hierro en el Occidente europeo refuerzan la hipotética adscripción cronocultural de torques y arracadas a contextos sistémicos prerromanos. La hipótesis alternativa resultaría enormemente excepcional, además de carecer de evidencias empíricas (González Ruibal 2006-07).

Por todas esas razones, la mayor parte de los investigadores defiende actualmente para la orfebrería protohistórica noroccidental una fase de formación inicial genéricamente datable en los finales de la Edad del Bronce, un desarrollo principal durante la Edad del Hierro -con eventual paroxismo en la segunda mitad del I milenio a.C.- y una marcada decadencia a partir de los tiempos iniciales de la romanización. Algunas voces han cuestionado este esquema, sugiriendo unas dataciones tardías e incluso en contextos de cambio de era y temprana romanización del noroeste, siempre teniendo en cuenta que muchos de estos objetos aparecieron en castros con niveles de ocupación o ergologías romano-imperiales (Peña 1992, 2003). 
Una importante contribución al debate deriva de la recuperación, en el castro pontevedrés de Troña, de un fragmento de torques en un nivel estratigráfico de relleno originado en un momento preaugústeo y asociado a cerámicas de producción local con formas y decoraciones claramente encuadrables en la II Edad del Hierro (Ladra 1999). Tal hallazgo demuestra que la producción de torques en el noroeste comienza antes de la ocupación romana, aun cuando pudiese continuarse después. Resulta más difícil, como se detallará en los apartados pertinentes, ofrecer una cronología absoluta más precisa para objetos o tipologías específicos. El problema está lejos de resolverse y, por tanto, nuestros argumentos serán por necesidad abiertos.

\section{MÉTODO ANALÍTICO}

El estudio de los dos objetos que se presentan en este artículo se enmarca en un proyecto más amplio de análisis de la orfebrería prehistórica actualmente depositada en diversos museos de la provincia de Lugo, cuyos resultados completos se publicarán más adelante. Entretanto, conviene señalar que estos dos son los únicos objetos en los que se detectó mercurio dentro de la muestra de unas cuarenta piezas, fundamentalmente torques y arracadas.

Los análisis se efectuaron con un aparato portátil de espectrometría de fluorescencia de rayos $\mathrm{X}$ por energías dispersivas (FRX), marca Innov-X Systems y modelo Alpha 8000 LZX, con un ánodo de plata y un detector SiPIN con una resolución de ca. $180 \mathrm{eV}$ FHWM para rayos X de $5.9 \mathrm{keV}$ (a $4000 \mathrm{cps}$ en el acero de referencia AISI 316), en un área de $6 \mathrm{~mm}^{2}$. Todos los análisis fueron realizados a $40 \mathrm{keV}, 30.5 \mu \mathrm{A}$, con un filtro de aluminio en el haz de rayos $\mathrm{X}$ y un tiempo de adquisición de 30 segundos por medición.

Los espectros fueron cuantificados empleando el software homónimo creado por Innov-X, y normalizados a $100 \%$ en peso, pero en todos los casos se verificó la presencia de los elementos identificados mediante investigación visual de los espectros. Es de particular relevancia para este estudio el problema analítico, señalado por Perea et al. (2008), de la identificación de mercurio en presencia de oro, dada la proximidad de los picos de ambos metales en el espectro. Como se muestra en la figura 1, el equipo empleado tiene suficiente resolución para separar estos picos. Por tanto, aun cuando la exactitud de los datos cuanti-

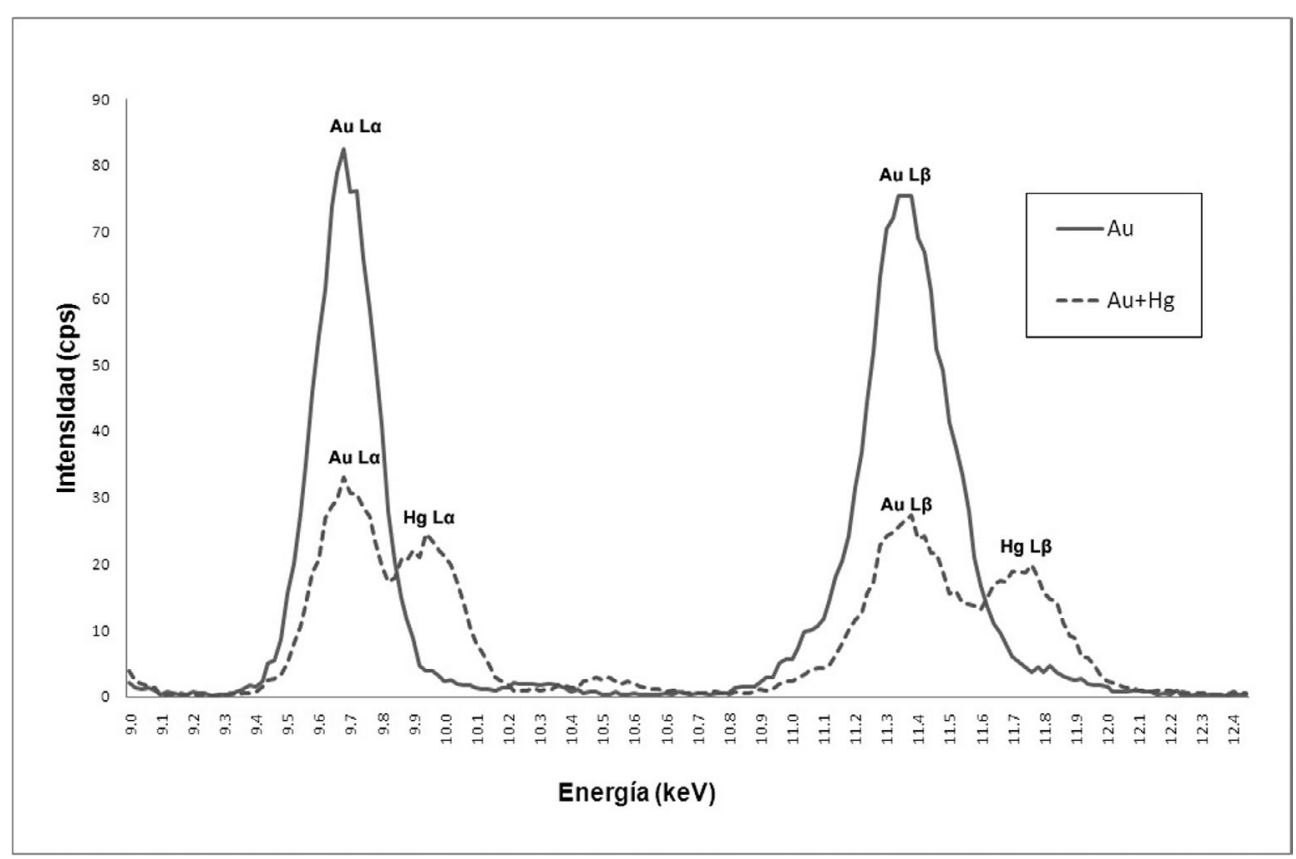

Fig. 1. Comparación de un área de interés de dos espectros de fluorescencia de rayos X. Se aprecia la resolución diferencial entre los picos espectrales de oro y mercurio cuando ambos están presentes en un mismo objeto analizado. 
tativos pueda estar afectada por el solapamiento entre picos espectrales, la presencia de mercurio en los análisis nos parece incuestionable. Para evitar riesgos de error, no reportamos ningún elemento cuya cuantificación fuese inferior a $0,2 \%$. Asimismo, no especificamos en nuestras tablas las concentraciones de hierro (en general $=$ $\leq 1 \%$ ), dado que este elemento puede verse muy afectado por contaminación superficial postdeposicional, ni de arsénico, ya que a niveles bajos nos resultó imposible distinguir con certeza los picos de este metal de los de plomo y mercurio.

\section{LOS EJEMPLOS GALAICOS}

\section{a) Un fragmento de torques de tipo ártabro del Castro de Viladonga}

La primera pieza que presentamos consiste en un fragmento de torques bastante deteriorado, pero de tipología reconocible, recuperado en el Castro de Viladonga (Castro de Rei, Lugo, Fig. 2) y actualmente depositado en su Museo Monográfico (MMCV n. ${ }^{\circ}$ inv. A70-606) (Arias 1983: 204, 1996: 105; Balseiro 2004: 194-195; Ladra y Martinón-Torres 2009). De este mismo yacimiento proceden 7 elementos de orfebrería: 2 torques de los denominados "de tipo ártabro", el fragmento distal de un tercero homólogo que tratamos en este artículo, una arracada "tipo sanguesuga", una sortija, un aro liso abierto de remates aguzados superpuestos y una pequeña lámina de difícil identificación funcional. Todos estos objetos fueron analizados, y sólo en este fragmento de tor-

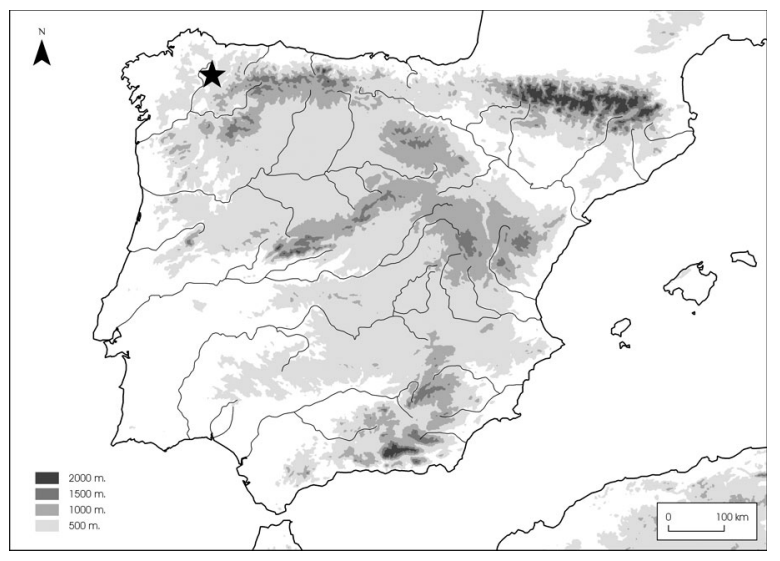

Fig. 2. Mapa de la Península Ibérica con la ubicación del Castro de Viladonga (Castro de Rei, Lugo). ques se detectó mercurio (Ladra y Martinón-Torres 2009). En su estado de conservación actual, incompleto y deformado, la pieza mide $7,8 \mathrm{~cm}$ de largo y pesa 14,04 g. Conserva tan sólo parte del aro, el cual es de sección circular y aparece retorcido. El remate también está fracturado (o quizás recortado deliberadamente) y se preserva tan sólo su mitad proximal, pero su forma globular hueca permite intuir que probablemente se trataría de un terminal piriforme, una tipología muy común en las zonas septentrionales del noroeste (Fig. 3A) (López Cuevillas 1932; Monteagudo 1952). La mayor peculiaridad formal de este objeto es un pequeño collarín o reborde perimetral dentado que abraza el punto de unión entre el aro y el remate, cubriendo así la eventual soldadura (Fig. 3B). Apenas conocemos un par de paralelos aproximados para este detalle en el ámbito de la orfebrería protohistórica noroccidental: un torques supuestamente procedente de la provincia de A Coruña (López Cuevillas 1951: 27; García-Vuelta 2007: 71-74) y otro de Vilas Boas, en Portugal (Santos Júnior y Silva 1965: Figs. 2, 3 y 4; Armbruster 2000: taf. 103, n. ${ }^{\circ} 4$ ). En otros ám-
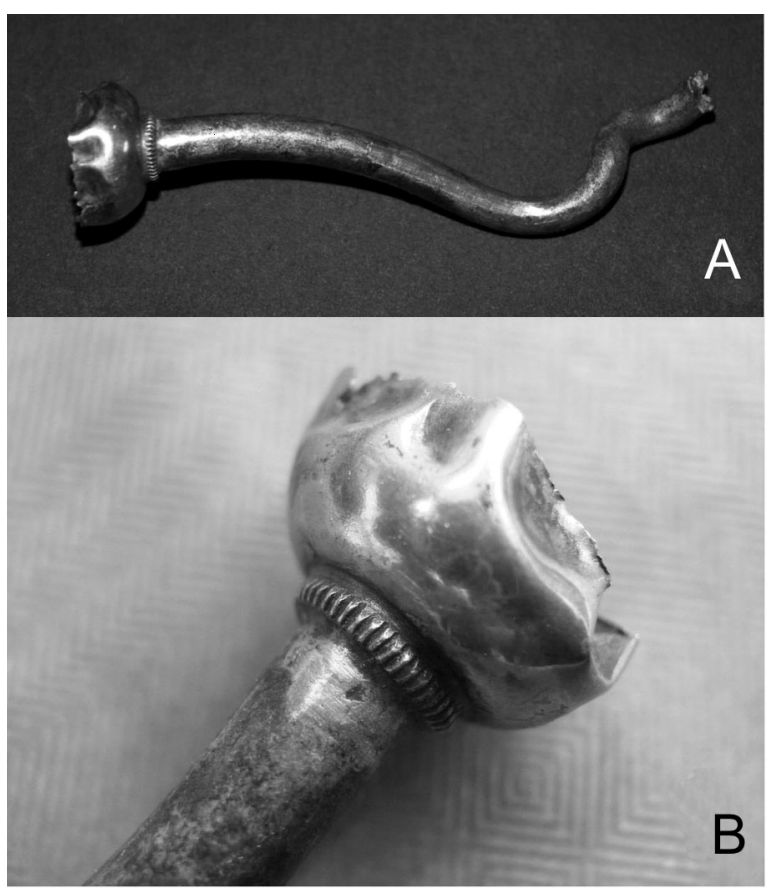

Fig. 3A. Fragmento de torques del castro de Viladonga (fotografía: Museo Monográfico do Castro de Viladonga). B. Detalle del engarce del aro al terminal (fotografía: Lois Ladra). 
bitos atlánticos podemos constatar semejantes analogías formales en un torques recuperado en el suroeste de Francia, en Civray-la-Forêt (Eluère 1987: 29, Fig. 13a; Duval y Eluère 1987), así como en alguno de los torques de Snettisham, en Gran Bretaña (Hautenauve 2004: 124), si bien éstos son tipológicamente muy diferentes al de Viladonga. Además del marcado deterioro formal del fragmento de torques que aquí nos ocupa, es significativa la apariencia superficial de su aro, que alterna zonas más doradas con otras prácticamente negras, donde el dorado parece haberse perdido por completo.

Como sucede con la mayor parte de los torques gallegos y como ya hemos referido anteriormente, la cronología de esta pieza es relativamente incierta. La mayoría de los autores contemporáneos ubica los torques con remates piriformes soldados al cuerpo principal de la pieza en el marco cronológico genérico de la II Edad del Hierro del noroeste, introduciendo cada investigador pequeñas matizaciones: siglos V-II a.C. (Silva 2007: 84 y 333), siglos III-I a.C. (Balseiro 1994: 46; Prieto 1996: 198). Sin embargo, el asentamiento de Viladonga estuvo habitado cuando menos desde finales de la II Edad del Hierro y hasta los últimos estertores de la antigüedad tardorromana (Arias y Fábregas 2003: 201), de modo que no puede descartarse una fecha más tardía para su último episodio de vida útil.

Los análisis de superficie realizados en diferentes partes del aro de este torques revelan que la plata es el elemento fundamental en su composición química, con cantidades moderadas de cobre, aunque se detectan concentraciones significativas de oro y mercurio en todas las áreas (Tab. 1). Para confirmar la posibilidad de un dorado al fuego, se analizó también la sección del aro en la zona fracturada. Aquí se detectó también una aleación de plata y cobre, pero los niveles de oro y mercurio son mucho más bajos, lo cual corrobora la impresión inicial de que estos últimos metales están concentrados en la superficie. En el remate no se detectó mercurio. Por el contrario, parece que esta pieza se fabricó a partir de una aleación de plata, oro y cobre con un contenido en plata excepcionalmente alto $(\sim 64 \%)$. Ello explicaría el color amarillo más verdoso del remate. Aún cuando las aleaciones de la orfebrería galaica de la II Edad del Hierro se caracterizan por ser marcadamente argentíferas (Montero y Rovira 1991; García-Vuelta y Montero 2007), los

\begin{tabular}{|l|c|c|c|c|c|c|c|}
\hline & $\mathbf{C u}$ & $\mathbf{A g}$ & $\mathbf{S b}$ & $\mathbf{A u}$ & $\mathbf{H g}$ & $\mathbf{P b}$ & $[\mathbf{A g} / \mathbf{( A g +} \mathbf{C u})]^{* \mathbf{1 0 0}}$ \\
\hline Torques MMCV A70-606 & & & & & & & \\
aro (zona de fractura) & 20,3 & 77,8 & - & 1,7 & 0,3 & - & 79 \\
aro & 13,9 & 72,1 & - & 7,4 & 6,7 & - & 84 \\
aro & 16,8 & 75,7 & - & 4,3 & 3,1 & - & 82 \\
aro & 12,6 & 79,2 & - & 4,3 & 3,9 & - & 86 \\
aro & 23,4 & 69,2 & - & 4,3 & 3,2 & - & 75 \\
terminal & 6,1 & 63,7 & - & 30,2 & - & - & 91 \\
terminal & 8,4 & 65,4 & - & 26,3 & - & - & 89 \\
Terminal en doble escocia & & & & & & & \\
$\quad$ MMCV LU-23 & & & & & & & \\
disco distal & & & & & & \\
disco distal & 21,5 & 68,9 & 1,1 & 3,8 & 4,0 & 0,7 & 76 \\
escocia (zona dorada) & 19,3 & 63,8 & 0,8 & 10,3 & 5,2 & 0,6 & 77 \\
escocia (zona oscura) & 13,9 & 31,6 & 0,5 & 46,8 & 6,9 & 0,2 & 69 \\
disco proximal & 56,2 & 29,3 & 1,9 & 7,0 & 2,7 & 3,0 & 34 \\
grieta en la unión disco dis- & 32,4 & 26,1 & 2,1 & 30,1 & 6,6 & 2,8 & 45 \\
$\quad$ tal/escocia & 33,4 & 41,2 & 2,3 & 16,4 & 4,4 & 2,4 & 55 \\
\hline
\end{tabular}

Tab. 1. Resultados analíticos por fluorescencia de rayos X portátil de dos fragmentos de torques dorados por amalgama de mercurio procedentes del noroeste de la Península Ibérica, conservados en el Museo Monográfico del Castro de Viladonga. Valores expresados en \% en peso y normalizados a 100\%. Inevitablemente, las composiciones químicas combinan la del dorado superficial y la del metal subyacente. En la última columna, los valores aproximan el contenido en plata de la aleación de plata y cobre sobre la que se practicó el dorado (asumiendo que no hay oro en esta aleación). 
niveles de plata en el terminal son demasiado altos incluso para estos estándares noroccidentales. De hecho, ninguno de los otros objetos de oro recuperados en el castro muestra composiciones en este rango (Ladra y Martinón-Torres 2009).

En cualquier caso, y antes de explorar en más detalle la relevancia del dorado por amalgama, esta pieza ilustra un aspecto ya conocido de la orfebrería protohistórica gallega y que destacamos en el estudio del conjunto de Viladonga (Ladra y Martinón-Torres 2009): la detección frecuente de varias "coladas" o aleaciones en la misma pieza, relevante para la interpretación arqueológica de los procesos técnicos, pero también para los estudios analíticos, que no pueden ceñirse a un único análisis.

\section{b) Un terminal en forma de doble escocia de procedencia incierta}

La procedencia de este segundo fragmento de torques correspondiente a otro ejemplar es lamentablemente incierta, ya que fue recuperado sin información relativa al lugar en que habría sido localizado antes de ser finalmente depositado por orden judicial en el Museo Monográfico del Castro de Viladonga con el número de inventario LU-23 (Ladra 2007). A pesar de nuestro actual desconocimiento sobre su contexto, su antigüedad y autenticidad se basarían en su tipología relativamente canónica, comparable a la de otras muchas piezas del noroeste, y en el hecho de que el anterior torques, recuperado en un contexto arqueológico claro, hace plausible que este objeto dorado al fuego también sea antiguo. No obstante, deberemos ser cautelosos en cualquier interpretación arqueológica derivada de su estudio.

El terminal en cuestión es del tipo conocido como "de doble escocia" (Fig. 4A) (López Cuevillas 1932: 118; Cardozo 1942: 93; Monteagudo 1952: 294-296). En su estado actual, sus ejes máximos tienen $41 \mathrm{~mm}$ de longitud y $34 \mathrm{~mm}$ de anchura, pesando 113,57 g (Ladra 2007: 168). Como en el caso anterior, la superficie del objeto alterna zonas doradas con otras más oscuras. En el disco proximal, el terminal muestra un hueco central cuadrado, lo cual indica que este remate se engarzaría en un aro de sección cuadrangular (Fig. 4B). Asumiendo que la pieza sea original y antigua, su cronología puede tan sólo estimarse a partir de otros remates similares encontrados en
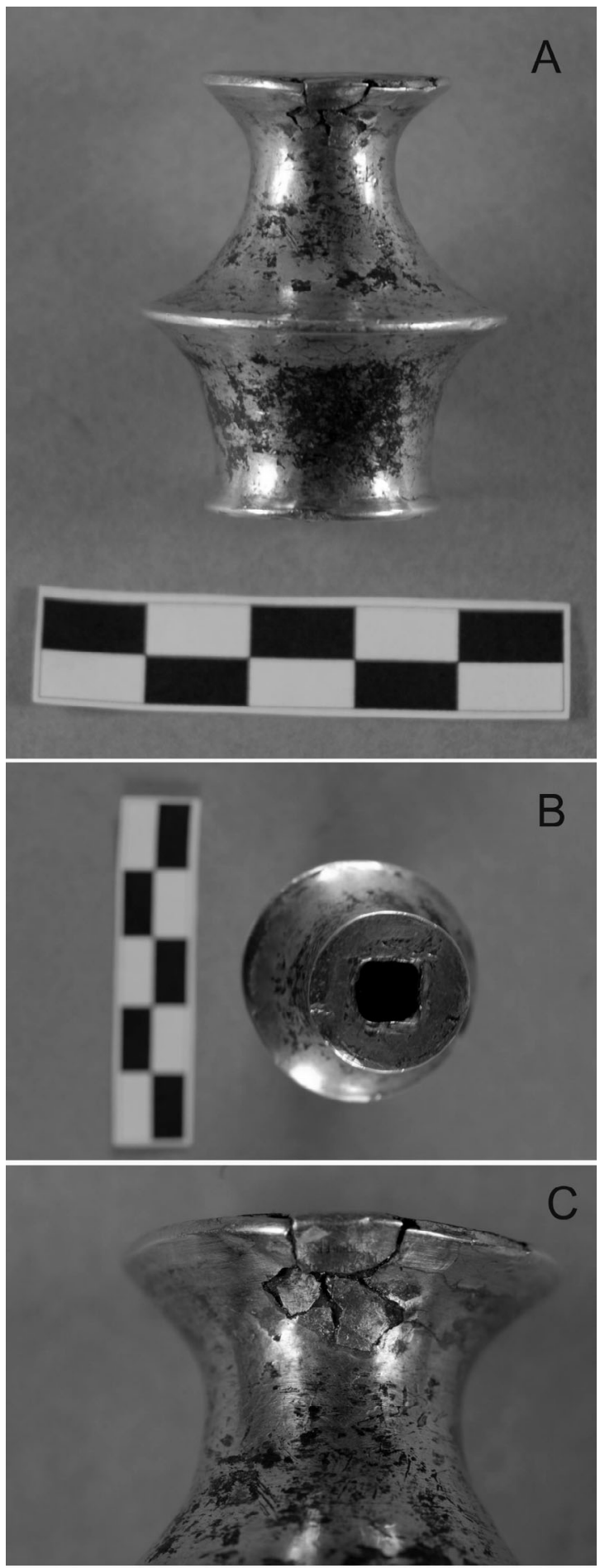

Fig. 4A. Terminal en forma de doble escocia LU-23. B. Detalle del disco proximal del terminal, mostrando el hueco para un aro de sección cuadrangular. C. Detalle de una zona fracturada (y reparada) del terminal en la que se puede apreciar la presencia del chapado que recubre un núcleo sólido (fotografías: Lois Ladra). 
yacimientos lucenses, asturianos o incluso del norte de Portugal. Diversos investigadores han planteado la existencia de morfotipos con terminales en forma de doble escocia repartidos geográficamente en una zona "astur-norgalaica" (Monteagudo 1952: 294-296) y otra "flaviense" (Cardozo 1942), ambos ubicables en un marco comprendido genéricamente entre los siglos $\mathrm{V}$ y I a.C. (Silva 2007: 84 y 333-335; Balseiro 1994: 47).

Como ya notó uno de nosotros en su estudio preliminar, la primera peculiaridad tecnológica de este terminal es que parece estar constituido por una chapa metálica que recubre un núcleo macizo (Ladra 2007: 168). Al menos, ésta es la impresión que se obtiene a partir de una pequeña fractura en el borde del disco distal, que revela la aparente existencia de este chapado (Fig. 4C). La considerable densidad de esta pieza sugiere que el núcleo probablemente también sea metálico. Para ilustrar este punto podemos comparar el peso de esta pieza $(113,57 \mathrm{~g})$, con el de un terminal hueco de la Colección "Soto Cortés" actualmente depositado en el Museo Arqueológico Nacional (n. ${ }^{\circ}$ inv. 33.136), cuyas dimensiones son prácticamente idénticas al ejemplar lucense, aunque con un peso notablemente inferior: 34,81 g (García-Vuelta 2007: 107). El color verdoso de los productos de corrosión que asoman por la fractura sugiere un núcleo de cobre o de una aleación de este metal, pero los análisis de FRX en esta zona de geometría complicada no fueron concluyentes (Tab. 1). El objeto no muestra ningún magnetismo cuando se le acerca un imán, lo cual indica que es improbable que su núcleo sea de hierro (Ladra 2007: 171). Sea como fuere, el terminal no se ajusta a las tecnologías habituales para estas piezas, que son a menudo huecas y, cuando son macizas, parecen haberse construido a partir de un único metal vaciado a la cera perdida (Armbruster y Perea 2000).

Los análisis de superficie arrojan pocas dudas acerca del empleo de la técnica de dorado por amalgama de mercurio (Tab. 1). Además de oro y mercurio, los elementos más abundantes son plata y cobre, lo cual indica que ésta sería la aleación sobre la que se practicó el dorado. En este caso, parecería que la capa dorada es más gruesa (o está mejor conservada) que en el anterior fragmento de torques, como indican los niveles de oro más elevados, mientras que el metal de base parecería ser más rico en cobre, tal y como se re- fleja en los valores de $[\mathrm{Ag} /(\mathrm{Ag}+\mathrm{Cu})]^{*} 100$, que son generalmente más bajos en el terminal en forma de doble escocia (Tab. 1). De todas maneras, debe recordarse que todos estos valores son aproximativos, dado que la emisión de FRX analizada procede del dorado superficial y, posiblemente, de parte del metal que subyace, sin que podamos separar ambos componentes. De potencial interés son las trazas de plomo y antimonio también detectadas. Cuantificar trazas de plomo en piezas ricas en oro y mercurio es difícil, dada la proximidad de los picos espectrales de estos tres metales. No obstante, el examen visual de los espectros sugiere que la presencia de plomo es real. Pequeñas cantidades de plomo han sido detectadas también en piezas protohistóricas doradas al fuego de la zona sur de la Península Ibérica (Perea et al. 2008). Si bien se han señalado los problemas asociados al dorado al fuego sobre metales ricos en plomo (Craddock 1977; Anheuser 1997), las cantidades de plomo aquí detectadas son mínimas y probablemente no afectaron al resultado de la técnica de dorado.

\section{DISCUSIÓN: ORÍGENES Y TRANSMISIÓN DEL DORADO POR AMALGAMA}

Las dos piezas aquí presentadas pueden atribuirse genéricamente a la orfebrería protohistórica de la II Edad del Hierro del noroeste. Por otra parte, ambas muestran peculiaridades que van más allá del empleo de la técnica del dorado al fuego. En el fragmento de torques de remate aparentemente piriforme, estas singularidades aparecen en el collar que rodea la unión entre aro y terminal, así como en el empleo de una aleación muy argentífera para este último. En el terminal con perfil en forma de doble escocia hemos resaltado la posible rareza de que el dorado se practicase sobre una chapa metálica que, a su vez, recubre un núcleo de otro metal.

En un estudio centrado en torques con terminales en doble escocia, Armbruster y Perea (2000) han destacado la gran variabilidad tecnológica que se esconde bajo la aparente homogeneidad tipológica de este tipo de remates. En este sentido, las singularidades constatadas aquí son verosímiles y no hacen sino ampliar el abanico de la variabilidad en la orfebrería galaica. Para los otros dos torques de remates piriformes del Cas- 
tro de Viladonga, hemos señalado (Ladra y Martinón-Torres 2009) la probabilidad de que fueran elaborados por orfebres diferentes, dada su heterogeneidad tecnológica. Por ejemplo, en al menos uno de ellos, el dorado se obtuvo por recubrimiento de una vara de cobre-plata, y no por amalgama. En general, este modelo sería coherente con la existencia de artesanos itinerantes que producirían objetos concretos en función de las demandas específicas de cada castro, una idea inicialmente propuesta por López Cuevillas (1932: 97) y respaldada posteriormente por muchos autores, entre ellos Armbruster y Perea (2000: 109). Como alternativa, también reconocida por estas autoras, podría sugerirse que los torques se obtuvieran mediante intercambio con otras comunidades del noroeste o a partir de determinados centros distribuidores. En cambio, parece improbable que todos los torques fuesen manufacturados por un orfebre local ubicado en cada castro.

Centrándonos ahora en los orígenes y difusión de la técnica del dorado por amalgama y considerando los nuevos datos aportados, planteamos una serie de hipótesis cuya confirmación o refutación dependerá de que obtengamos más analíticas y dataciones más precisas.

1. Como ya se indicó, el uso del dorado al fuego se documenta por vez primera en la Península Ibérica en la segunda mitad del I milenio a.C., explicándose por transmisión tecnológica directa desde la zona mediterránea, o bien por invención local independiente (Perea et al. 2008). Teniendo en cuenta esta hipótesis, podría sugerirse que los orfebres que manufacturaron los torques estudiados ( 0 , al menos, el de Viladonga, cuya antigüedad es incontestable) podrían proceder de la zona central o mediterránea de la península, donde el mercurio abunda en forma de cinabrio y donde la técnica ya se conocía. La importación de torques argénteos desde la zona ibérica al noroeste ya ha sido propuesta por autores como Balseiro (2000), pero el estilo claramente "castreño" del torques que aquí nos ocupa nos hace pensar más bien en una producción realizada en el noroeste, y no en una importación. La existencia de yacimientos de cinabrio en el noroeste peninsular (Luque et al. 1999), varios con evidencias de trabajos extractivos romanos y posiblemente anteriores (Matías et al. 2000-01; Neira et al. 2007) hace todavía más plausible que los torques fuesen fabricados en esta región.
Tendríamos, por tanto, un orfebre itinerante respondiendo a la demanda y a los gustos locales con sus peculiares conocimientos tecnológicos.

2. La posibilidad de un orfebre del interior peninsular trabajando en el noroeste, aun cuando no puede rechazarse, se antoja un tanto controvertida a la luz de las concomitancias formales y conceptuales fundamentalmente atlánticas y centroeuropeas que caracterizan a los torques galaicos, frente al influjo tecnológico y ornamental de inspiración parcialmente mediterránea de las arracadas (Silva 2007: 331-332; Castro 1990: 149-150 y 154-155; Calo 1993: 130-131). Es necesario por ello considerar la posibilidad de que la técnica entrase en el noroeste peninsular por vía marítima. En las Islas Británicas, hay evidencias arqueológicas y analíticas del dorado al fuego en torques del siglo I a.C. (Northover y Anheuser, 2000; D. Hook, com. pers. 2010). De particular interés resulta el hecho de que, según los precarios datos existentes, el empleo de esta técnica parece perder intensidad durante dos siglos, para ganar vigor en torno al siglo II d.C. De esta forma, si el conocimiento de esta técnica llegó al noroeste gallego por vía atlántica, tal suceso podría haber sucedido poco antes del cambio de era. Ello es hasta cierto punto coherente con las fechas finales que se proponen para el uso de este tipo de torques galaicos, y nos permitiría así ajustarlas un poco más.

3. Aun cuando carecemos de datos para corroborar la anterior hipótesis, la posibilidad de transmisión tecnológica entre las Islas Británicas y el noroeste peninsular por vía atlántica nos obliga a plantearnos la hipótesis de un flujo tecnológico en sentido contrario, es decir, la difusión de esta técnica desde la zona gallega al Atlántico Norte por vía marítima. No en vano, Northover y Anheuser (2000: 112) señalan a Iberia e Italia como "obvios candidatos" para explicar la transmisión de esta técnica a Gran Bretaña y, como señalamos, los yacimientos de cinabrio no se restringen a la zona meridional sino que también estaban al alcance de los orfebres del noroeste. La escasez de dorados por amalgama documentados en el noroeste ibérico (véanse resultados en Montero y Rovira 1991; García-Vuelta y Montero 2007; Martinón-Torres y Ladra 2009) nos hace pensar que una transmisión tecnológica desde esta zona y hacia Gran Bretaña es improbable, pero dada la relativa parquedad de estudios analí- 
ticos tampoco podemos rechazar esta hipótesis con total rotundidad.

4. Una cuarta hipótesis, que invalidaría la segunda y tercera, sería plantear que los torques galaicos con dorado al fuego fueran tardíos, habiéndose introducido en el noroeste tras la dominación romana. La prolongada ocupación diacrónica del asentamiento humano en Viladonga apoyaría parcialmente tal hipótesis, como lo harían también las propuestas que sugieren que la orfebería de "estilo castreño" siguió produciéndose tras la conquista (Peña 2003: 141-142). Sin embargo, de ser éste el caso, cabría preguntarse por qué no tenemos más evidencias del empleo de dorado al fuego en la orfebrería galaica de la II Edad del Hierro. Como la técnica es frecuente y está perfectamente controlada en el período romano (Northover y Anheuser 2000; Oddy 2000), esperaríamos encontrar una mayor incidencia de este recurso tecnológico si la orfebrería castreña datara de esta época. Sea como fuere, conviene no olvidar que el castro de Viladonga también ha proporcionado varias dataciones radiocarbónicas prerromanas con las cuales se podría relacionar eventualmente la numerosa orfebrería de tradición indígena recuperada en este poblado galaico-romano (Arias y Fábregas 2003: 198; González Ruibal 2006-2007: 421).

5. Finalmente, y como quinta opción, podría sugerirse que estas dos piezas constituyen importaciones, ya sea de otras zonas de la península ya de la Europa Atlántica. No obstante, como recordaremos, su peculiar estilo formal y ornamental se antoja tan al gusto autóctono que parece más razonable pensar que, quienquiera que las manufacturase, lo hiciera bajo influencia estilística o a demanda local en el noroeste.

Cualquiera que sea la respuesta última a estas cuestiones, está claro que el estudio de la orfebrería de la fachada atlántica durante la II Edad del Hierro deberá atender más a la transferencia de conocimientos tecnológicos específicos, más allá de las influencias estilísticas, e incluso a la posible emigración de orfebres cubriendo grandes distancias geográficas (entre el noroeste peninsular y las Islas Británicas) o culturales (entre las diversas regiones de la Península Ibérica). Quizá no esté de más recordar aquí la leyenda de Creidne el aurífice, según la cual este orfebre irlandés, "contemporáneo de las luchas de los Firbolgs y de los Tuatha de Dannan, se ahogó en el mar cuando volvía a Erin después de comprar oro en Hispania" (López Cuevillas 1951: 8).

\section{CONCLUSIÓN}

El tema de los orígenes y difusión de la técnica del dorado por amalgama de mercurio continúa planteando numerosos interrogantes. En particular, la escasez de datos impide determinar con certeza si la técnica tuvo un origen monogenético o poligenético. La cronología temprana resulta tan vaga y precaria que parecería coherente la existencia de un único foco de invención en la China del siglo V a.C., al que sucedería su progresiva difusión hacia Occidente -una hipótesis que todavía no se ha refutado convincentemente-. Sin embargo, otras propuestas indican lo contrario, y en particular se ha sugerido que pudo existir un foco de invención independiente en la zona sur de la Península Ibérica (Perea et al. 2008). Sin más hallazgos acompañados de dataciones más seguras y precisas, la cuestión continuará abierta. En todo caso, la estrategia de investigación será más completa si consideramos los estilos tecnológicos de una forma integral, más allá de la identificación de la técnica del dorado al fuego. Otros factores como la cantidad de mercurio residual en superficie (que puede indicar la temperatura y duración del proceso, así como la proporción de $\mathrm{Hg}: \mathrm{Au}$ en la amalgama original), el espesor de la capa dorada, la composición del metal base y otros aspectos tecnológicos (como la presencia/ausencia de soldaduras, remates huecos, pulidos y otras dimensiones tipológicas en las mismas piezas; Armbruster y Perea 2000), pueden proporcionar información más rica para determinar si la técnica del dorado al fuego encaja dentro de una o más líneas de transmisión tecnológica.

Los ejemplos noroccidentales de dorado al fuego presentados aquí no resuelven esta cuestión. Al contrario, la enriquecen, ya que plantean la posibilidad de que la transmisión tecnológica englobe no sólo vías mediterráneas sino también influencias atlánticas. El estilo de las piezas y la disponibilidad de mercurio en la zona nos llevan a pensar que estos torques fueron fabricados en el noroeste peninsular, pero no podemos resolver concluyentemente el origen de la técnica o del orfebre; ni siquiera las fechas. Esperamos que tales complicaciones estimulen a otros investigadores a retomar un problema cuya solución sigue siendo elusiva. La gradual integración de cuestiones históricas con respuestas que requieren estudios arqueométricos, así como la creciente disponibili- 
dad de técnicas analíticas, acrecientan nuestra curiosidad y optimismo al respecto.

\section{AGRADECIMIENTOS}

Al personal del Museo del Castro de Viladonga, en especial a Felipe Arias, Elena Varela, María Consuelo Durán y Marta Cancio, su valiosa ayuda para facilitar nuestro estudio de las piezas. Carme Rovira Hortalá informó acerca de las piezas catalanas, y Duncan Hook sobre su investigación en curso sobre los torques de Snettisham. Dos evaluadores anónimos proporcionaron útiles comentarios y sugerencias.

\section{BIBLIOGRAFÍA}

Anheuser, K. 1996: "Cold and hot mercury gilding of metalwork in Antiquity". Bulletin of the Metals Museum 26: 47-51.

Anheuser, K. 1997: "The practice and characterization of historic fire gilding techniques". Journal of the Minerals, Metals and Materials Society 49 (11): 58-62.

Arias, F. 1983: "Novos materiais arqueolóxicos do Castro de Viladonga no Museo de Lugo". Boletín do Museo Provincial de Lugo 1: 203-208.

Arias, F. 1996: "Fragmento de torques de Viladonga". En A. Álvarez (coord.): El oro y la orfebrería prehistórica de Galicia. Diputación Provincial de Lugo. Lugo: 105.

Arias, F. y Fábregas, R. 2003: "Datacións radiocarbónicas do Castro de Viladonga (Lugo)". Gallaecia 22: 193-210.

Armbruster, B. R. 2000: Goldschmiedekunst und Bronzetechnik. Studien zum Metallhandwerk der Atlantischen Bronzezeit auf der Iberischen Halbinsel. Monographies Instrumentum 15, Éditions Monique Mergoil. Montagnac.

Armbruster, B. R. y Perea, A. 2000: "Macizo/hueco, soldado/fundido, morfología/tecnología. El ámbito tecnológico castreño a través de los torques con remates en doble escocia". Trabajos de Prehistoria 57 (1): 97-114.

Balseiro, A. 1994: El oro prerromano de la provincia de Lugo. Diputación Provincial. Lugo.

Balseiro, A. 2000: "El torques argénteo de Mondoñedo: un producto foráneo". Boletín do Museo Provincial de Lugo 9: 17-26.

Blet-Lemarquand, M.; Téreygeol, F.; Gratuze, B. y Barrandon, J.-N. 2009: "Technical study of fire-gilded Aksumite silver coins: first results". En $2^{\text {nd }}$ International Conference Archaeometallurgy in
Europe: Selected Papers (Grado/Aquileia, 2007): 464-476. Milán.

Calo, F. 1993: A Cultura Castrexa. A Nosa Terra. Vigo.

Cardozo, M. 1942: "Uma notável peça de joalharia primitiva". Anais da Faculdade de Ciências do Porto 27: 89-100.

Castro, L. 1990: Os torques prehistóricos. Universidade de Santiago de Compostela. Santiago de Compostela.

Craddock, P. T. 1977: "The composition of copper alloys used by Greek, Etruscan and Roman Civilisations 2: The Archaic, Classical and Hellenistic Greeks". Journal of Archaeological Science 4: 103-123.

Drayman-Weisser, T. (ed.) 2000: Gilded Metals: History, Technology and Conservation. Archetype Publications. Londres.

Duval, A. y Eluère, C. 1987: "Le torque gaulois en or de Civray-la-Forêt (Indre-et-Loire)". Revue du Louvre 37 (4): 256-267.

Eluère, C. 1987: "Celtic gold torcs". Gold Bulletin 20 (1/2): 22-37.

García-Vuelta, O. 2007: Orfebrería castreña en el Museo Arqueológico Nacional. Ministerio de Cultura. Madrid.

García-Vuelta, O. y Montero, I. 2007: “Aportaciones analíticas sobre orfebrería castreña: Problemas de caracterización de piezas de la colección del Museo Arqueológico Nacional (Madrid)". Conimbriga 46: 89-115.

González Ruibal, A. 2006-2007: Galaicos. Poder y comunidad en el Noroeste de la Península Ibérica. Museo Arqueolóxico e Histórico. A Coruña.

Hautenauve, H. 2004: "Technical and metallurgical aspects of Celtic gold torcs in the British Isles $\left(3^{\text {rd }}-1^{\text {st }}\right.$ c. BC)”. En A. Perea, I. Montero y O. García-Vuelta (eds.): Tecnología del oro antiguo: Europa y América. Anejos del Archivo Español de Arqueología XXXII. Madrid: 119-126.

Jett, P. y Chase, W. T. 2000: "The gilding of metals in China". En T. Drayman-Weisser (ed.): Gilded Metals: History, Technology and Conservation. Archetype Publications. Londres: 145-155.

La Niece, S. y Craddock, P. (eds.) 1993: Metal Plating and Patination: Cultural, Technical and Historical Developments. Butterworth-Heinemann. Oxford.

Ladra, L. 1999: "Algunhas consideracións sobre un fragmento de torques inédito recentemente aparecido no Castro de Troña". Castrelos 12: 67-80.

Ladra, L. 2007: "Dous novos remates de torques castrexos". Anuario Brigantino 30: 167-178.

Ladra, L. y Martinón-Torres, M. 2009: "Variacións tecnolóxicas e preferencias culturais: estudo analítico dos ouros do castro de Viladonga". Croa 19: $32-43$. 
Lins, P. A. y Oddy, W. A. 1975: "The origins of mercury gilding". Journal of Archaeological Science 2: 365-373.

López Cuevillas, F. 1932: Os torques do Noroeste Hispánico. Arquivos do Seminario de Estudos Galegos IV. Seminario de Estudos Galegos. Santiago de Compostela.

López Cuevillas, F. 1951: Las joyas castreñas. CSIC. Madrid.

Luque, C.; García Iglesias, J. y García Coque, P. 1989. "Carácterísticas geoquímicas de los cinabrios de la Cordillera Cantábrica (NW de España): Utilidad en prospección". Trabajos de Geología 18: 13-11.

Matías Rodríguez, R.; Alonso Herrero, E.; Neira Campos, A.; Pérez Ortiz, L. y San Román Fernández, F. 2000-2001: "Una explotación minera de minium (cinabrio) atribuible a época romana en Miñera (León-España)". Lancia. 4: 127-140.

Monteagudo, L. 1952: "Torques castreños de alambres enrollados". Archivo Español de Arqueología 86: 287-296.

Montero, I. y Rovira, S. 1991: "El oro y sus aleaciones en la orfebrería prerromana". Archivo Español de Arqueología 64: 7-21.

Murakami, R. 2000: "Archaeological gilded metals excavated in Japan”. En T. Drayman-Weisser (ed.): Gilded Metals: History, Technology and Conservation. Archetype Publications. Londres: 157-168.

Neira Campos, A.; Alonso Herrero, E.; Matías Rodríguez, R.; Fuertes Prieto, N.; Pérez Ortíz, L. y San Román Fernández, F. 2007: "La más antigua minería metálica en tierras de León”. En J. Celis, G. Delibes de Castro, J. Fernández Manzano y L. Grau Lobo (eds.): El hallazgo leonés de Valdevimbre y los depósitos del Bronce Final Atlántico en la Península Ibérica. Estudios y Catálogos 17. Museo de León. León: 220-236.

Northover, P. y Anheuser, K. 2000: "Gilding in Britain: Celtic, Roman and Saxon". En T. Drayman-Weisser, (ed.): Gilded Metals: History, Technology and Conservation. Archetype Publications. Londres: 109-121.
Oddy, A. 1993: "Gilding of metals in the Old World". En S. La Niece y P. Craddock (eds.): Metal Plating and Patination: Cultural, Technical and Historical Developments. Butterworth-Heinemann. Oxford: 171-181.

Oddy, A. 2000: "A history of gilding with particular reference to statuary". En T. Drayman-Weisser (ed.): Gilded Metals: History, Technology and Conservation. Archetype Publications. Londres: 1-19.

Peña, A. de la 1992: “El primer milenio a.C. en el área gallega: génesis y desarrollo del mundo castreño a la luz de la arqueología". Complutum 2-3: 373-392.

Peña, A. de la 2003: Galicia. Prehistoria, castrexo e primeira romanización. A Nosa Terra. Vigo.

Perea, A., Montero, I., Gutiérrez, P.C. y Climent-Font, A. 2008: "Origen y trayectoria de una técnica esquiva: el dorado sobre metal". Trabajos de Prehistoria 65(2): 117-130.

Prieto, S. 1996: "Los torques castreños del Noroeste de la Península Ibérica". Complutum 7: 195-223.

Rovira Hortalà, M.C. 1999: "La metalurgia". En M. A. Martín, R. Buzó, J. B. López y M. Mataró (eds.): Excavacions arqueologiques a l'Illa d'en Reixac (1987-1992). Monografies d'Ullastret, 1. Museu d'Arqueologia de Catalunya. Girona: 225-248.

Santos Júnior, J. R. D. y Silva, O. F. 1965: “O torques de Vilas Boas (Vila Flor)". Revista de Guimarães 75: 137-152.

Silva, A. C. F. 2007: A Cultura Castreja no Noroeste de Portugal. Câmara Municipal de Paços de Ferreira-Museu Arqueológico da Citania de Sanfins-Centro de Arqueología Castreja e Estudos Célticos. Paços de Ferreira. 2. ${ }^{\mathrm{a}}$ ed.

Zarzalejos Prieto, M.; Arévalo González, A. y Fernández Ochoa, C. 1999: "Tránsito, comercio y actividad económica en la Sisapo altoimperial". En R. Balbín Berhmann y P. Bueno Ramírez (eds.): II Congreso de Arqueología Peninsular (Zamora, 1996), IV Arqueología Romana y Medieval: 171-181. Zamora. 